\title{
An analysis of cranial radiography in post-mortem recognition
}

\author{
Imen B ${ }^{1,2}$, Farid B ${ }^{1}$, Khaoula B ${ }^{3}$, Mokhtar $\mathbf{H}^{3}$ and Bouharati Saddek ${ }^{2 *}$ \\ ${ }^{1}$ Radiology department, Faculty of Medicine, Ferhat Abas UFAS Setif1 University, Algeria \\ ${ }^{2}$ Laboratory of Intelligent Systems, Ferhat Abas UFAS Setif1 University, Algeria \\ ${ }^{3}$ Laboratory of Health and Environment, Faculty of Medicine, UFAS Setif1, Setif, Algeria
}

\begin{abstract}
Aim: Often post-mortem radiography as a judicial procedure is intended to know the causes of death. X-rays are systematic on putrefied, charred or severely altered bodies when identifying a body. Nowadays other radiological techniques are used in post mortem recognition. In the case of collective disasters (war, air accident, or industrial ...etc.) the task is easy when comparing ante-mortem radiographs. In the absence of these, vestibular craniography and positional morpho-metric analysis is necessary. Specific characters of a skull are taken into account in this study. It refers us to his race as the first identification.
\end{abstract}

Method: In this study, a database is based on the data that specifying each ethnic group (Gallo-Romans, Japanese, Ainu, Amerindians, Melanesians, African Blacks, Australians, Tasmanians ...). Each group is distinguished by specific characters (the shape of the structures and for their position in the axes, their structure and their reciprocal articulation). From measurements made on radiography skull and artificial neural network analysis, it will be possible to attribute this to the ethnic group to which it belongs.

Conclusion: In this study, we consider these characters (distances, circumferences, curve, volumes, and angles) are considered as input variables of the network. These variables are related to an output variable that refers to the individual race. This can be a valuable tool for identification in forensic medicine.

\section{Introduction}

Nowadays, the identification of victims of disasters in the 187-member countries of Interpol adopts a procedure for the identification of victims in any type of disaster, whatever the cause or magnitude [1]. Especially when it comes to accidents followed by incineration, forensic investigations are very complex $[2,3]$. This is seen in cases of natural disasters such as aircraft accidents or wars [4]. The identification often goes through a cranial x-ray. Analyzes performed in this one is based on the frontal sinuses. This often makes the difference between individuals by their volumes as well as by the position and arrangement of their cavities [5]. These characteristics morphologically differentiate populations in different parts of the world [6-9]. However, norms differ between Japanese comparative studies, and studies on Caucasian and British female individuals show differences in the characteristics of lateral cephalograms between these ethnic groups [10]. If differences exist between sexes, they also vary with age. Radiological images reflect biological age [11]. This estimate is based on biological changes during growth [12]. It is recognized that the development of women matures before that of men [13]. In any case, the dental age is the closest to the actual skeletal age [14].

In this study, it is recognized that in the case of the absence of antemortem data, identification becomes very difficult. Various cranial morphological parameters taken in radiology are translated into numerical data. This is compared to a database encompassing these same parameters of the different standardized ethnic races. An artificial neural network model is proposed in this data analysis.

\section{Cranial morphological parameters}

What is observed is that ethnic groups differ in their vestibular orientations. By comparing these vestibulars by superimposing them in the axes, it becomes easy to differentiate between the ethnic characters and their stability as elements of specific characters. If this allows for ethnic recognition, it remains to consider age and gender variations.

Some studies take as parameters: craniocervical angle (NS/ $\mathrm{OPT}$ ), the length of the anterior cranial base (NS), anterior facial height (N-Me), posterior facial height (S-Go), the angle of maxillary prognathism (SNA), angle of mandibular prognathism (SNB), difference between angles SNA and SNB (ANB angle), the angle of the basal planes of the jaws (SpP/MP), cranial base angle (NSB), and the angle of facial convexity (NA/Apg) [15]. Methods that are widely used in forensic investigations in autopsies and palaeodemography are based on linear anthropometric measurements and calculations of skull surfaces [16]. Others considered 24 points as radiographic localized landmarks as angular measurements and seven linear measures of craniofacial morphology. (Angular measurement: Sella-nasion-point $A$ angle, ANB Point A-nasion-point $B$...etc.) And (Linear measurements: N-S Anterior cranial base length, $\mathrm{N}-\mathrm{Me}$

Correspondence to: Saddek B, Laboratory of Intelligent Systems, Ferhat Abas UFAS Setif1 University, Algeria, E-mail: sbouharati@univ-setif.dz

Key words: radiography, cranometry, recognition, forensics, fuzzy logic

Received: January 02, 2018; Accepted: January 19, 2018; Published: January 23, 2018 
Total anterior face height, N-ANS Upper anterior face height). These benchmarks are analyzed by the Cephalo Power Software (ReazaNet Co., Ltd., Tokyo, Japan) [17].

\section{Radiological recognition techniques}

In forensic, radiology has become an indispensable tool in identification. This is due to technological developments in this area. This tool is better understood by practitioners and investigators [18]. The radiology practiced mainly for medico-legal comparisons concerns dental and cranial radiology $[19,20]$. In addition to conventional $\mathrm{X}$-rays, nowadays computed tomography is widely used. This technique greatly facilitates the identification of individuals. Studies report that $\mathrm{CT}$ is a key tool in clinical diagnosis and can also be a support for identification in forensic investigations [21]. Also, CT scans are often used before conventional autopsy [22,23] on decomposed bodies [24] or even sometimes on human remains allowing identification and trace back to the cause of death [25]. What is also accepted by the authors is that computed tomography post-mortem contributes reliably to human identification by its precision and objectivity [26]. This imaging technique makes it possible to collect a large amount of data from the multi-detector CT and reconstitution it in multi-plan for a numerical analysis. In the case of a judicial inquiry, a copy must be authenticated by the competent authority. Data transmission is then possible for a possible remote analysis.

The identification comparison result is generally represented by the probability of meeting corresponding correct characteristics on the probability of encountering incorrect characteristics [27].

\section{$P($ match $) \mid$ correct identification \\ $\overline{P(\text { match }) \mid \text { incorrect identification }}$}

\section{Artificial neural networks analysis}

Artificial neural networks are inspired by the biological neural network as in humans and the way they process information. An artificial neural network system is the interconnection of several neurons involved in the processing of information. These systems have found applications in different fields of biology and medicine either in diagnosis or in image processing [28]. It's mainly about creating two input-output spaces. The input space includes several interconnected networks representing the input variables. The output space represents the variable that expresses the result. It is then necessary to make the correspondence between the two spaces from the measured real values. This phase is learning the network. There, the network establishes a function of correspondence between the two spaces. With each variation of the input and output values, the network adjusts the function for optimization until it reaches the minimum error. The advantage of neural networks is that it offers the possibility of introducing a large number of variables. By varying each at the input and the output, it is not necessary to change the network; the adjustment of the transfer function is affected by the variation of the weights which are mathematical coefficients. Once the function is optimized with a maximum of data in the learning phase, it becomes possible to introduce variables randomly at the input to instantly read the result at the output. The network just refers to the function already established. The basic architecture of a network is the succession of three layers: input layer, hidden layer and output layer (Figure 1).

In this study, it is a matter of building a network with the input variables that constitute the various cranial parameters in correspondence with the ethnic races of the individuals. These data are available in the literature $[17,29]$. These input variables include angular

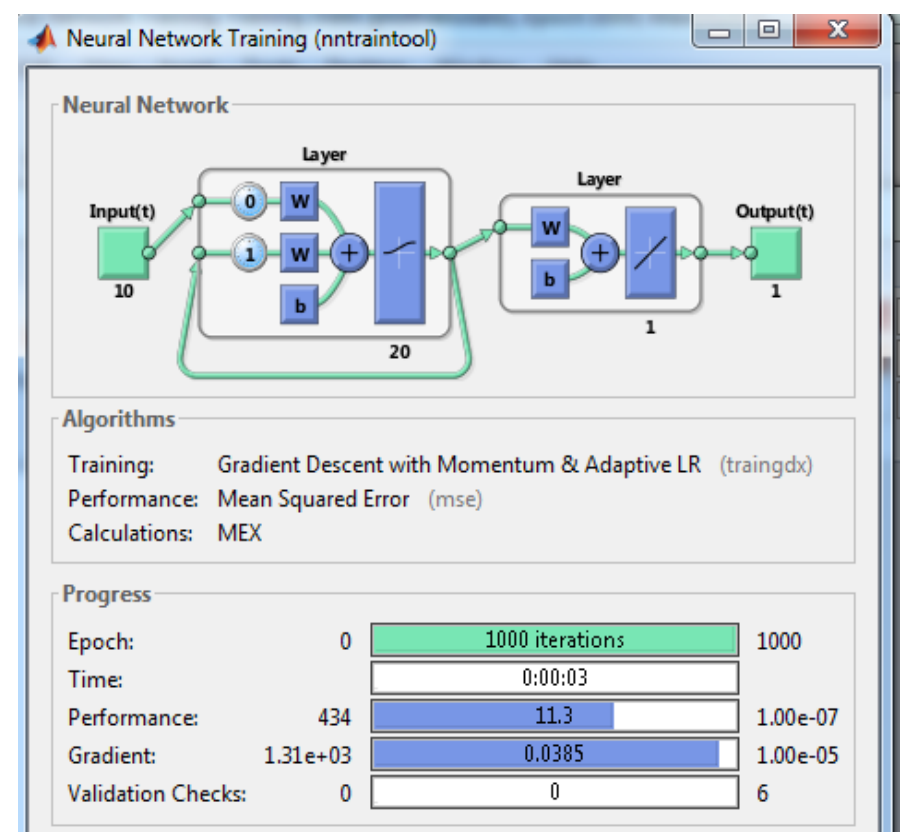

Figure 1. Block diagram of the system

measurements such as: Sella-nasion-point $A$ angle, Sella-nasionpoint $B$ angle, ANB Point A-nasion-point B, Facial angle, Convexity, Mandibular plane, Gonial angle, $Y$-axis, Ramus inclination, Interincisal angle, $Z$ angle, Nasolabial angle, Mentolabial angle, Occlusal plan angle. and linear measurements such as: Anterior cranial base length, Total anterior face height, Upper anterior face height, Lower anterior face height, The distance between the most anteriorly placed point and the $N A$ line, The distance between the most anteriorly placed point and the $N B$ line, Wits Distance between the AO and BO points on the occlusal plane. During this phase the network establishes the optimized match (learning) function. Subsequently, radiological images of the different parts of the skulls of the individuals to be identified are converted into numerical variables. These values are introduced as input variables to the established system. This allows direct and instantaneous reading of the output variable that refers to the ethnic race of the individual.

\section{Result}

After assigning different values as variables to the input representing angular measurements and linear measurements in correspondence with the races, the transfer function is established. During this learning phase, we see that the gradient is 0.038 and a reading rate at 0.17 to 1000 iterations (Figure 2).

\section{Conclusion}

In forensic investigations, different techniques have been developed in recent years. However, in certain geographical areas, particularly in underdeveloped countries, radiography remains the most used. Also, in the absence of anatomical data relating to individuals when they were alive, it becomes very difficult to establish identification. Faced with this situation and in natural disasters especially where accidents are followed by incineration (aircraft accidents for example) and a loss of reliable data to identification, this study proposes a model for comparing cranial data to the basics of standardized data. From radiological images converted to numerical data taken on skulls, these are processed using artificial neural networks. The algorithm allows introducing these data to instantly read the ethnic race of the individual with great precision. 


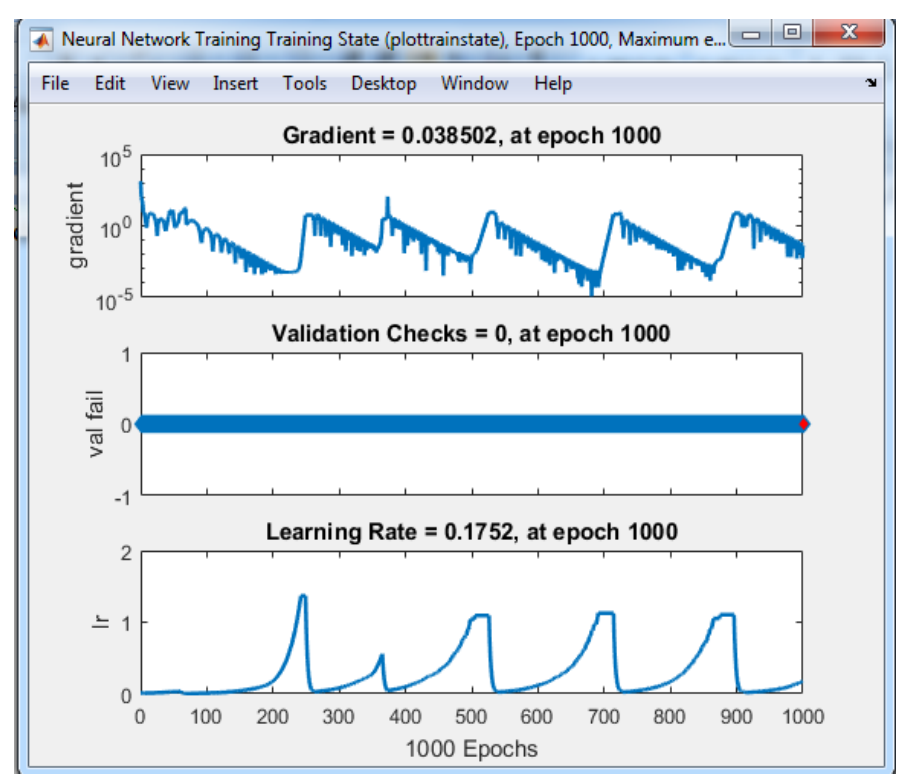

Figure 2. Training results

\section{References}

1. INTERPOL (1996) Interpol Resolution, Disaster Victim Identification.

2. Valenzuela A, Marques T, Exposito N, Martín-De Las Heras S, García G (2002) Comparative study of efficiency of dental methods for identification of burn victims in two bus accidents in Spain. Am J Forensic Med Pathol 23: 390-393. [Crossref]

3. Meyer HJ (2003) The Kaprun cable car fire disaster aspects of forensic organisation following a mass fatality with 155 victims. Forensic Sci Int. 138: 1-7. [Crossref]

4. Lain R, Griffiths C, Hilton JM (2003) Forensic dental and medical response to the Bali bombing: a personal perspective. Med J Aust 179: 362-365. [Crossref]

5. da Silva RF, Prado FB, Caputo IG, Devito KL, Botelho Tde L, et al. (2009) The forensic importance of frontal sinus radiographs. J Forensic Leg Med 16: 18-23. [Crossref]

6. Downs WB (1948) Variations in facial relationships; their significance in treatment and prognosis. Am J Orthod 34: 812-840.

7. Alcalde RE, Jinno T, Pogrel MA, Matsumura T (1998) Cephalometric norms in Japanese adults. J Oral Maxillofac Surg 56: 129-134. [Crossref]

8. Nanda R, Nanda RS (1969) Cephalometric study of the dentofacial complex of North Indians. Angle Orthod 39: 22-28. [Crossref]

9. Drummond RA (1968) A determination of cephalometric norms for the Negro race. $A m$ J Orthod 54: 670-682. [Crossref]

10. Ishii N, Deguchi T, Hunt NP (2002) Craniofacial differences between Japanese and British Caucasian females with a skeletal Class III malocclusion. Eur J Orthod 24: 493-499. [Crossref]

11. Simpson DE, Dontu VS, Stephens SE, Archbold LJ, Lowe V, et al. (2005) Large variations occur in bone density measurements of children when using different software. Nucl Med Commun 26: 483-487. [Crossref]
12. Beauthier JP (2008). Traité de médecine légale. Bruxelles, Belgium: De Boeck.

13. Dedouit F, Savall F, Mokrane F-Z, Rousseau H, Crub'ezy E, et al. (2014) Virtual anthropology and forensic identification using multidetector CT. $\mathrm{Br} J$ Radiol 87:20130468. [Crossref]

14. Schaefer M, Scheuer L, Black SM (2009) Juvenile osteology: a aboratory and field manual. London, UK: Academic Press.

15. Vladanka V, Jasna P, Amila V, Brankica M, Mirjana K, et al. (2017) Radiographic cephalometry analysis of head posture and craniofacial morphology in oral breathing children. Vojnosanit Pregl 74: 1048-1053.

16. Lottering N, MacGregor MD, Barry MD, Reynolds MS, Gregory LS (2014) Introducing standardized protocols for anthropological measurement of virtual sub-adult crania using computed tomography. Journal of Forensic Radiology and Imaging 2: 34-38

17. Mohamed A, Tetsutaro Y, Mohamed N, Daisuke T, Yu Hikita TN, et al. (2016) Evaluation of the Craniofacial Morphology of Egyptian Adults Undergoing Orthodontic Treatment. Dentistry 6:6.

18. Christensen AM, Hatch GM, Brogdon BG (2014) Principles and perspectives in forensic radiology. Journal of Forensic Radiology and Imaging.

19. Pfaeffli M, Vock P, Dirnhofer R, Braun M, Bolliger SA, et al. (2007) Post-mortem radiological CT identification based on classical ante-mortem X-ray examinations. Forensic Sci Int 171: 111-117. [Crossref]

20. Silva RF, Pinto RN, Mendes SDSC, Marinho DEA, Teixeira EA (2007) Forensic importance of the wrist joint radiographs to human identification. Rev Imagem 29: 165-167.

21. Silva RF, Botelho TL, Prado FB, Kawagushi JT, Daruge Junior E, et al. (2011) Human identification based on cranial computed tomography scan: a case report. Dentomaxillofac Radiol 40: 257-261. [Crossref]

22. Dedouit F, Telmon N, Costagliola R, Otal P, Joffre F, et al. (2007) Virtual anthropology and forensic identification: report of one case. Forensic Sci Int 173: 182-187. [Crossref]

23. Thali MJ, Yen K, Vock P, Ozdoba C, Kneubuehl BP, et al. (2003) Image-guided virtua autopsy findings of gunshot victims performed with multi-slice computed tomography (MSCT) and magnetic resonance imaging (MRI) and subsequent correlation between radiology and autopsy findings. Forensic Sci Int 138: 8-16. [Crossref]

24. Thali MJ, Yen K, Schweitzer W, Vock P, Ozdoba C, et al. (2003) Into the decomposed body -forensic digital autopsy using multislice-computed tomography. Forensic Sci Int 134: 109-114.

25. Myers JC, Okoye MI, Kiple D, Kimmerle EH, Reinhard KJ (1999) Three-dimensional (3-D) imaging in post-mortem examinations: elucidation and identification of cranial and facial fractures in victims of homicide utilizing 3-D computerized imaging reconstruction techniques. Int J Legal Med 113: 33-37. [Crossref]

26. Grivas CR, Komar DA (2008) Kumho, Daubert, and the nature of scientific inquiry: implications for forensic anthropology. J Forensic Sci 53: 771-776. [Crossref]

27. Christensen AM (2005) Testing the reliability of frontal sinuses in positive identification. J Forensic Sci 50: 18-22. [Crossref]

28. Khenchouche A, Bouharati K, Bouharati S, Mahnane A, Hamdi-Cherif M (2017) Post Mortem Interval: Necrobiome Analysis Using Artificial Neural Networks. Computational Biology and Bioinformatics. 5: 90-96.

29. Pellerin C, et Fenart R (1984) Comparaisons globales entre neuf populations de crânes récents, étudiées en orientation vestibulaire Bull, et Mém. de la Soc. d'Anthrop. de Paris, t. 2, série XIV 67-82.

Copyright: C2018 Imen B. This is an open-access article distributed under the terms of the Creative Commons Attribution License, which permits unrestricted use, distribution, and reproduction in any medium, provided the original author and source are credited. 